JIPS, Vol. 2 No. 1

Halaman: 127-133

Mei 2021
Jurnal Inovasi Pembelajaran di Sekolah

DOI: https://doi.org/10.51874/jips.v2i01.21

ISSN 2774-9363 (Cetak)

ISSN 2774-9746 (Online)
JIPS

Sekolah

\title{
Efektivitas Model Pembelajaran Inkuiri Terhadap Hasil Belajar
}

\author{
Nur Khoiri \\ Program Studi Magister Pendidikan IPA Universitas PGRI Semarang \\ Jalan Sidodadi Timur 24 Semarang \\ e-mail: nurkhoiri@upgris.ac.id
}

\begin{abstract}
Abstrak: Penelitian ini bertujuan untuk mengetahui efektivitas model pembelajaran inkuiri terhadap hasil belajar siswa. Penentuan sampel penelitian dengan menggunakan teknik cluster random sampling sehingga diperoleh kelas eksperimen dan kelas kontrol. Uji normalitas menggunakan uji Lilliefors dan uji homogenitas menggunakan uji Bartllet. Uji hipotesis menggunakan uji $\mathrm{t}$ dan efektivitas model pembelajaran inkuiri dilihat dari uji Gain. Berdasarkan analisis data hasil penelitian diperoleh skor $t_{\text {hitung }}>t_{\text {tabel }}(4,93>1,67)$, sehingga $\mathrm{H}_{\mathrm{o}}$ ditolak. Hal ini menunjukkan bahwa model pembelajaran inkuiri efektif terhadap hasil belajar. Analisis Gain kelas eksperimen mempunyai kriteria tinggi $(0,70)$ dan kelas kontrol mempunyai kriteria sedang $(0,48)$.
\end{abstract}

Kata kunci: efektivitas, inkuiri, hasil belajar

Abstract: The purpose of the research is to know the effectiveness of inquiry learning model on student learning outcomes. Determination of the sample using cluster random sampling technique to obtain the experimental class and control class. Test for normality using Lilliefors test and test for homogeneity using Bartllet test. Hypothesis testing using t test and effectiveness of inquiry learning model showed by Gain test. Based on the analysis data, the result of this research is gotten with score $t_{\text {count }}>t_{\text {table }}$ (4.93>1.67), so Ho is rejected. This shows that the inquiry learning model is effective on learning outcomes. Gain analysis of an experimental class has high criterion (0.70) and the control class has medium criteria (0.48).

Keywords: effectiveness, inquiry, learning outcomes

\section{PENDAHULUAN}

Pengembangan kemampuan sains siswa merupakan salah satu kunci keberhasilan dalam proses pembelajaran. Belajar sains tidak cukup hanya menghafal materinya saja tetapi juga harus dapat memahami konsep-konsep di dalamnya. Belajar adalah modifikasi atau memperteguh kelakuan melalui pengalaman. Menurut pengertian ini, belajar merupakan suatu proses, suatu kegiatan dan bukan suatu hasil atau tujuan. Belajar bukan hanya mengingat, akan tetapi lebih luas dari itu, yaitu mengalami (Hamalik, 2011, Mardapi, 2017).

Fisika merupakan salah satu bagian dari sains yang mempelajari tentang sifat materi, gerak dan dan fenomena lain. Jadi dalam pengajaran fisika tenaga pendidik tidak hanya menyampaikan materi konsepsi saja, tetapi juga menekankan pada proses dan dapat menumbuhkan sikap ilmiah pada siswa salah satunya menjadikan siswa memiliki kemauan kuat dan kreatif dalam menemukan hal-hal baru dalam bidang fisika (Egger, A. dkk. 2017). 
Hasil observasi di sekolah ditemukan bahwa pembelajaran Fisika sekarang ini masih menggunakan model pembelajaran yang berpusat pada guru. Dalam hal ini siswa berperan sebagai individu yang pasif dengan tugas hanya sekedar mendengarkan, mencatat dan menghafal informasi yang diberikan oleh guru. Pembelajaran yang seperti itu dapat mempengaruhi tercapainya tujuan pembelajaran.

Setelah mengetahui perlunya sebuah proses dalam belajar untuk mencapai suatu keberhasilan dalam kegiatan pembelajaran, maka yang menjadi tindakan selanjutnya adalah bagaimana mengoptimalkan kegiatan belajar yang terarah dalam tujuan yang bermakna. Dengan kata lain, perlu adanya sebuah model yang cocok bagi program pengajaran yang demikian. Model belajar mengajar dapat dikelompokkan menjadi dua kutub yang berbeda. Di satu pihak adalah model belajar-mengajar dimana siswa terlibat dalam usaha mencari dan menemukan, sedangkan pada kutub yang lain keterlibatan siswa sangat terbatas.

Seperti proses pembelajaran Fisika yang lebih menekankan pada proses dan menumbuhkan sikap ilmiah, maka pembelajaran yang sesuai adalah proses pembelajaran yang melibatkan siswa. Dalam pembelajaran ini siswa dituntut lebih aktif dalam menemukan suatu konsep atau prinsip dari suatu materi, Model pembelajaran yang melibatkan siswa dalam proses pembelajaran salah satunya adalah model pembelajaran inkuiri (Khoiri, dkk. 2020).

Model pembelajaran inkuiri merupakan model pembelajaran yang melibatkan pemprosesan informasi. Sedangkan menurut Carin dan Sund (1975) dalam Mulyasa (2013: 108) inkuiri merupakan proses dari investigasi suatu masalah. Jadi melalui pembelajaran inkuiri ini siswa mampu menemukan masalah-masalah dilingkungan sekitar yang berhubungan dengan materi pelajaran sehingga siswa dapat terlibat aktif dalam proses belajar-mengajar.

Menurut hasil penelitian yang dilakukan oleh Kristianingsih (2010) mengenai pembelajaran inkuiri, menunjukkan bahwa pengajaran dengan model inkuiri dengan metode pictorial riddle dapat meningkatkan hasil belajar siswa.

Berdasarkan uraian di atas, dilakukan penelitian dengan judul "Efektivitas Model Pembelajaran Inkuiri Terhadap Hasil Belajar Siswa".Inkuiri dapat diartikan sebagai penyelidikan Sedangkan dalam Enco Mulyasa (2013: 108), Carin dan Sund mengemukakan bahwa: Inquiry adalah the process of investigating a problem. Adapun Piaget mengemukakan bahwa metode inquiry merupakan metode yang mempersiapkan peserta didik pada situasi untuk melakukan eksperimen sendiri secara luas agar melihat apa yang terjadi, ingin melakukan sesuatu, mengajukan pertanyaan-pertanyaan dan mencari jawabannya sendiri serta menghubungkan penemuan yang satu dengan penemuan yang lain, membandingkan apa yang ditemukan dengan apa yang ditemukan peserta didik lain.

Inkuiri mengandung proses mental yang lebih tinggi tingkatannya seperti merumuskan masalah, merancang eksperimen, mengumpulkan data dan menganalisis data, menarik kesimpulan dan lain sebagainya (Abdurohman, 2017). Melalui proses inkuiri ini siswa diharapkan dapat membangun pengetahuannya sendiri dan mempunyai sikap objektif, jujur, hasrat ingin tahu dan sebagainya.

Penelitian ini berusaha menjawab pertanyaan: "Bagaimana efektivitas model pembelajaran inkuiri terhadap hasil belajar siswa?". Berdasarkan pertanyaan tersebut, penelitian ini mengajukan hipotesis alternatif yaitu model pembelajaran inkuiri efektif terhadap hasil belajar siswa. Sedangkan hipotesis nol yaitu model pembelajaran inkuiri tidak efektif terhadap hasil belajar siswa. Secara umum penelitian ini bertujuan untuk mengetahui efektivitas model pembelajaran inkuiri terhadap hasil belajar siswa.

\section{METODE PENELITIAN}

Penelitian ini merupakan penelitian kuantitatif. Dalam penelitin ini menggunakan dua variabel, yaitu variabel bebas dan variabel terikat. Variabel bebas dalam penelitian ini adalah model inkuiri. Sedangkan variabel terikatnya adalah hasil belajar. 
Desain penelitian ini menggunakan pretest-posttest control group design. Sebelum pembelajaran siswa diberikan pretest untuk mengetahui kondisi awal siswa. Kemudian untuk mengukur kondisi akhir siswa setelah diberi perlakuan, siswa diberikan posttest.

Metode pengumpulan data dengan menggunakan teknik dokumentasi dan teknik tes. Hasil belajar siswa diperoleh dari tes pilihan ganda yang diberikan kepada siswa. Hasil belajar siswa ini kemudian digunakan untuk uji hipotesis dan uji kriteria efektivitas model pembelajaran. Untuk mengetahui kriteria efektivitas model pembelajaran digunakan analisis menggunakan uji Gain sebagai berikut:

$$
g=\frac{S_{\text {post }}-S_{\text {pre }}}{S_{\text {max }}-S_{\text {pre }}}
$$

Kriteria efektivitas model pembelajaran adalah sebagai berikut:

Tabel 1 Kriteria Indeks Gain

\begin{tabular}{cc}
\hline Indeks Gain & Keterangan \\
\hline $\mathrm{g} \geq 0,7$ & Tinggi \\
$0,3 \leq \mathrm{g}<0,7$ & Sedang \\
$\mathrm{g}<0,3$ & Rendah \\
\hline
\end{tabular}

Uji normalitas dan homogenitas digunakan untuk mengetahui apakah kelompok eksperimen dan kontrol berangkat dari keadaan yang sama. Analisis uji normalitas menggunakan metode Lilliefors dan uji homogenitas menggunakan uji Bartllet Uji t digunakan untuk mengetahui model pembelajaran inkuiri efektif terhadap hasil belajar siswa.

\section{HASIL DAN PEMBAHASAN}

Analisis data awal digunakan untuk mengetahui keadaan awal sampel. Data yang digunakan adalah nilai UTS semester genap. Analisis data awal dilakukan untuk mengetahui apakah kedua sampel berawal dari kemampuan yang sama. Pada tahap ini analisis yang dilakukan adalah uji normalitas dan uji homogenitas.

Hasil analisis uji normalitas mengetahui normalitas sampel dilakukan dengan menggunakan uji Lilliefors adalah sebagai berikut:

Tabel 2. Hasil Uji Normalitas

\begin{tabular}{ccccc}
\hline Kelompok & $\mathrm{N}$ & $\mathrm{L}_{\mathrm{o}}$ & $\mathrm{L}_{\text {tabel }}$ & Kesimpulan \\
\hline Eksperimen & 34 & 0,0926 & 0,1519 & $\begin{array}{c}\text { Berdistribusi } \\
\text { normal }\end{array}$ \\
Kontrol & 32 & 0,0927 & 0,1566 & $\begin{array}{c}\text { Berdistribusi } \\
\text { normal }\end{array}$ \\
\hline
\end{tabular}

Kriteria pengujiannya adalah $\mathrm{H}_{\mathrm{o}}$ diterima jika $\mathrm{L}_{\mathrm{o}}<\mathrm{L}_{\text {tabel }}$ maka sampel berdistribusi normal. Dari tabel 2 diketahui bahwa pada kelas eksperimen dengan $\mathrm{n}=34$ diperoleh $\mathrm{L}_{\mathrm{o}}=0,0926$ dan $\mathrm{L}_{\text {tabel }}=0,1519$, dengan demikian $\mathrm{L}_{\mathrm{o}}<\mathrm{L}_{\text {tabel }}$ yang berarti kelompok eksperimen berdistribusi normal. Sedangkan untuk kelompok kontrol dengan $\mathrm{n}=32$ diperoleh $\mathrm{L}_{\mathrm{o}}=0,0927$ dan $\mathrm{L}_{\text {tabel }}=$ 0,1566, dengan demikian $\mathrm{L}_{\mathrm{o}}<\mathrm{L}_{\text {tabel }}$ yang berarti kelompok kontrol berdistribusi normal. Jadi dapat disimpulkan bahwa kedua sampel berdistribusi normal.

Hasil analisis uji homogenitas untuk mengetahui apakah sampel diperoleh dari populasi yang homogen atau tidak adalah sebagai berikut: 
Tabel 3. Hasil Uji Homogenitas

\begin{tabular}{lcccl}
\hline Kelompok & $\mathrm{N}$ & $\chi^{2}$ & $\chi^{2}$ tabel & Kesimpulan \\
& & & & \\
\hline Eksperimen & 34 & & & \\
& & 0,29 & 3,84 & $\begin{array}{l}\text { Sampel } \\
\text { Homogen }\end{array}$ \\
Kontrol & 32 & & & \\
& & & & \\
\hline
\end{tabular}

Dari tabel 3 diketahui bahwa untuk $\alpha=5 \%$ dengan $\mathrm{dk}=(\mathrm{n}-1)$ diperoleh $\chi_{\text {tabel }}^{2}=3,48$. Kriteria $\mathrm{H}_{\mathrm{o}}$ diterima jika $\chi_{\text {hitung }}^{2}<\chi_{\text {tabel }}^{2}$. Hasil perhitungan didapatkan $\chi_{\text {hitung }}^{2}<\chi_{\text {tabel }}^{2}$ yaitu $0,29<3,84$ sehingga dapat disimpulkan bahwa sampel berasal dari populasi yang homogen.

Analisis akhir menggunakan nilai pretest-posttest dari soal yang telah dikerjakan oleh siswa. Dari nilai pretest-posttest tersebut dilakukan uji hipotesis dengan menggunakan uji-t dan uji Gain untuk mengetahui kriteria efektivitas model inkuiri.

Untuk mengetahui hasil belajar siswa yang mendapatkan pembelajaran menggunakan model inkuiri lebih baik dibandingkan hasil belajar siswa yang menggunakan model pembelajaran inkuiri dianalisis menggunakan uji-t.

Hipotesis statistik yang akan diuji adalah:

$$
\begin{aligned}
& \mathrm{H}_{\mathrm{a}}: \mu_{1}>\mu_{2} \\
& \mathrm{H}_{\mathrm{o}}: \mu_{1}=\mu_{2}
\end{aligned}
$$

Kriteria pengujian adalah $\mathrm{H}_{\mathrm{a}}$ diterima apabila $t_{\text {hitung }}>\mathrm{t}_{\text {tabel }}$ dengan $\mathrm{dk}=\mathrm{n}_{1}+\mathrm{n}_{2}-2$ dengn taraf nyata $\alpha=5 \%$ dan untuk harga $\mathrm{t}_{\text {hitung }} \leq \mathrm{t}_{\text {tabel }}$ maka $\mathrm{H}_{\mathrm{a}}$ ditolak. Hasil analisis uji-t dapat dilihat pada tabel 4 berikut:

Tabel 4. Hasil Uji-t Satu Pihak

\begin{tabular}{ccc}
\hline & Eksperimen & Kontrol \\
\hline$\sum$ & 2630 & 2115 \\
$\bar{x}$ & 82,19 & 70,50 \\
$\mathrm{~N}$ & 32 & 30 \\
$1 / \mathrm{n}$ & 0,03 & 0,03 \\
$\mathrm{~s}_{\mathrm{i}}^{2}$ & 69,25 & 105,78 \\
$\mathrm{~S}$ & 9,32 & \\
$\mathrm{t}_{\text {hitung }}$ & 4,93 & \\
$\mathrm{t}_{\text {tabel }}$ & 1,67 & \\
\hline
\end{tabular}

Berdasarkan perhitungan analisis data posttest hasil belajar siswa kelas kontrol dan kelas eksperimen diperoleh $\mathrm{t}_{\text {hitung }}=4,93$ dan $\mathrm{t}_{\text {tabel }(0,95: 60)}=1,67$. Karena $\mathrm{t}_{\text {hitung }}>\mathrm{t}_{\text {tabel }}$ yaitu 4,93 $>1,67$ maka $\mathrm{H}_{\mathrm{o}}$ ditolak. Hal ini menyatakan bahwa hasil belajar kelompok eksperimen lebih baik dibandingkan kelompok kontrol. Jadi model pembelajaran inkuiri efektif terhadap hasil belajar siswa.

Perhitungan Gain digunakan untuk menunjukkan efektivitas model pembelajaran inkuiri terhadap hasil belajar siswa. Nilai Gain didapatkan dari selisih nilai posttest dan nilai pretest. Hasil analisis uji Gain dapat dilihat pada tabel 5 berikut:

Tabel 4. Hasil Uji Gain Kelas Eksperimen dan Kontrol

\begin{tabular}{llll}
\hline Kelas & pretest & posttest & $<\mathrm{g}>\quad$ Kriteria \\
\hline
\end{tabular}




\begin{tabular}{lllll}
\hline Eksperimen & 40,31 & 82,19 & 0,70 & Tinggi \\
Kontrol & 43,17 & 70,5 & 0,48 & Sedang \\
\hline
\end{tabular}

Hasil perhitungan didapatkan $\langle\mathrm{g}>$ untuk kelas eksperimen 0,70 dan $\langle\mathrm{g}>$ untuk kelas kontrol 0,48. Nilai tersebut kemudian diinterpretasikan ke dalam kriteria nilai Gain. Pada kelas eksperimen mempunyai kriteria tinggi sedangkan pada kelas kontrol mempunyai kriteria sedang. Jadi dapat diketahui bahwa model inkuiri mempunyai tingkat keefektifan tinggi terhadap hasil belajar.

Berdasarkan analisis data baik kelas eksperimen maupun kelas kontrol mengalami peningkatan hasil belajar yang baik. Akan tetapi peningkatan pada kelas eksperimen lebih tinggi dibandingkan kelas kontrol. Hasil rata-rata pretest kelas eksperimen sebesar 40,31 dan pada kelas kontrol sebesar 43,17. Sedangkan rata-rata hasil posttest kelas eksperimen sebesar 82,19 dan pada kelas kontrol 70,50.

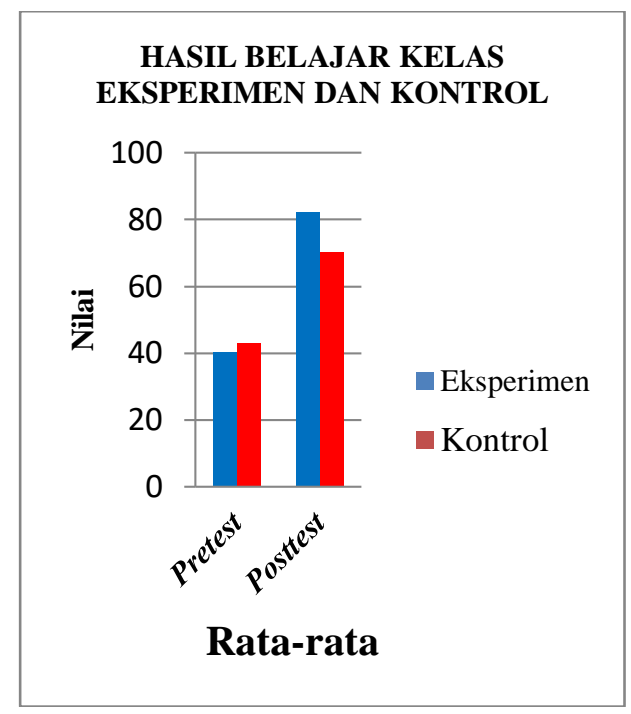

Gambar 1. Diagram Hasil Belajar Siswa

Nilai pretest menunjukkan kemampuan awal siswa. Terlihat dari gambar 1 hasil pretest kelas kontrol menunjukkan hasil yang lebih baik dibandingkan kelas eksperimen. Selisih ratarata hasil pretest kelas eksperimen dan kelas kontrol adalah 2,86. Sedangkan pada hasil posttest kelas eksperimen menunjukkan hasil yang lebih baik. Selisih rata-rata hasil posttest kelas eksperimen dan kontrol adalah 11,69. Terlihat bahwa ada perbedaan selisih rata-rata antara hasil pretest dan posttest. Perbedaan tersebut terpaut nilai sebesar 8,83. Faktor yang mempengaruhi perbedaan selisih rata-rata kedua kelas adalah penggunaan model pembelajaran, serta karakteristik siswa itu sendiri.

Analisis tahap akhir dilakukan untuk mengetahui model pembelajaran inkuiri lebih baik dibandingkan dengan model pembelajaran konvensional. Nilai posttest dari masing-masing kelas digunakan untuk analisis tahap akhir. Data dianalisis dengan menggunakan uji-t diperoleh $t_{\text {hitung }}$ sebesar 4,93 dan $t_{\text {tabel }}$ sebesar 1,67 sehingga $t_{\text {hitung }}>t_{\text {tabel }}$. Hal tersebut menunjukkan bahwa $H_{a}$ diterima yang berarti model pembelajaran inkuiri efektif terhadap hasil belajar siswa. 


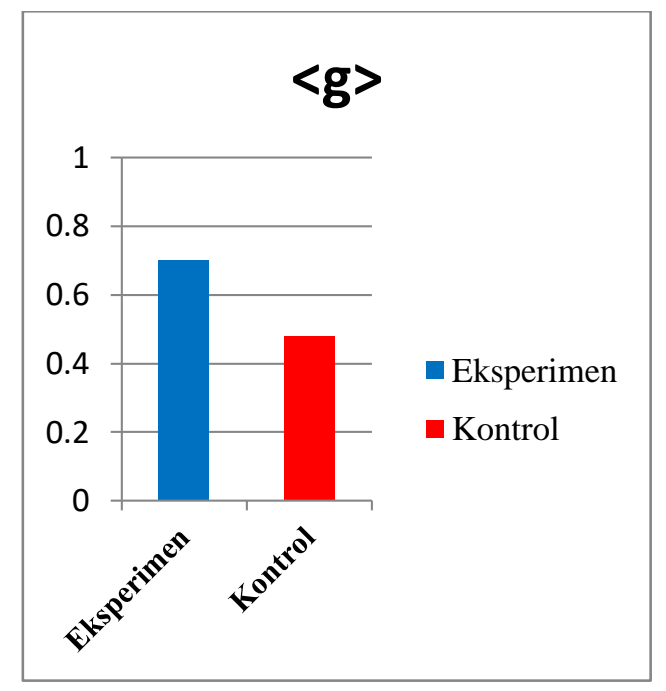

Gambar 2 Diagram Hasil Analisis Uji Gain

Kriteria efektivitas model pembelajaran inkuiri diketahui dari analisis Gain. Uji Gain diperoleh dari perbandingan antara nilai posttest dan nilai pretest. Berdasarkan gambar 5.2 kelas eksperimen mempunyai nilai $\langle\mathrm{g}\rangle$ sebesar 0,70 yang berarti mempunyai kriteria tinggi dan kelas kontrol mempunyai nilai $\langle\mathrm{g}>$ sebesar 0,48 yang mempunyai kriteria sedang. Pencapaian nilai Gain pada kelas eksperimen tersebut tidak terlepas dari aktivitas siswa pada saat pembelajaran. Siswa sangat antusias sekali saat pembelajaran berlangsung karena siswa melakukan beberapa percobaan untuk menemukan suatu pengetahuan atau konsep baru bagi mereka. Hasil analisis uji Gain menunjukkan bahwa model inkuiri mempunyai kriteria efektivitas yang tinggi terhadap hasil belajar siswa.

Perbedaan hasil belajar siswa antara kelas eksperimen dan kontrol dikarenakan dalam pembelajaran inkuiri siswa lebih banyak diberi kesempatan untuk membangun konsep pengetahuannya sendiri. Untuk dapat membangun konsep pengetahuannya ini siswa melaksanakan langkah-langkah pembelajaran seperti merumuskan masalah, merumuskan hipotesis, melakukan eksperimen, mengumpulkan data, menguji hipotesis dan merumuskan kesimpulan. Hal tersebut sesuai dengan penelitian Sochibin et al. (2009) bahwa dengan menggunakan model pembelajaran inkuiri terpimpin dapat meningkatkan pemahaman konsep siswa.

Secara umum penelitian ini dapat mengambil hal penting yaitu penggunaan model inkuiri memberikan dampak yang positif terhadap hasil belajar siswa. Model inkuiri memberi kesempatan kepada siswa untuk mengembangkan rasa ingin tahunya dan memberikan kesempatan kepada siswa untuk menemukan jawaban atas pertanyaan yang diajukan.

\section{SIMPULAN}

Berdasarkan pembahasan diperoleh kesimpulan bahwa model pembelajara inkuiri efektif terhadap hasil belajar siswa, karena pada proses pembelajaran siswa sangat antusias dan aktif untuk menemukan suatu pengetahuan baru bagi mereka. Selain itu kriteria efektivitas kelas eksperimen menunjukkan kriteria tinggi sedangkan pada kelas kontrol menunjukkan kriteria sedang. 


\section{DAFTAR PUSTAKA}

Abdurohman, 2017 Efektivitas dan Kendala Pembelajaran Sains Berbasis Inkuiri terhadap Capaian Dimensi Kognitif Siswa: Meta Analisis. Jurnal Keguruan dan Ilmu Tarbiyah Vol.02. 1. $1-9$

Arikunto, Suharsimi. 2009. Dasar - Dasar Evaluasi Pendidikan (Edisi Revisi). Jakarta: PT Bumi Aksara.

Djamarah, Syaiful Bahri. 2011. Psikologi Belajar. Jakarta: Rhineka Cipta.

Egger, A. E., Kastens, K. A., \& Turrin, M. K. 2017. "Sustainability, the Next Generation Science Standards, and the Education of Future Teachers". Journal of Geoscience Education, 65 (2): 168-184.

Hamalik, Oemar. 2011. PROSES BELAJAR MENGAJAR. Jakarta: Bumi Aksara.

Jati, Bambang M. E dan Tri Kuntoro P. 2010. FISIKA DASAR. Yogyakarta: ANDI.

Kristianingsih, D.D., et al. 2010. Peningkatan Hasil Belajar Siswa Melalui Model Pembelajaran Inkuiri Dengan Metode Pictorial Riddle Pada Pokok Bahasan Alat-Alat Optik Di Smp. Jurnal Pendidikan Fisika Indonesia. 6 (2010): 10-13. Universitas Negeri Semarang.

Mardapi, D. 2017. Pengukuran, Penilaian, dan Evaluasi Pendidikan. Yogyakarta: Parama Publishing.

Mulyasa, E. 2013. Menjadi Guru Profesional. Bandung: Remaja Rosdakarya.

N. Khoiri, Choirul H, Hadhijah A. 2020. Pembelajaran inkuiri terbimbing berbantuan alat peraga konstanta pegas digital untuk meningkatkan keterampilan generik sains. Physics Education Research Journal. 2. 2. 131-140. Faculty of Science and Education, UIN Walisongo Semarang

Siregar, E dan Hartini Nara. 2010. Teori Belajar dan Pembelajaran. Bogor: Ghalia Indonesia.

Slameto. 2010. Belajar dan Faktor-faktor yang Mempengaruhi. Jakarta: Rineka Cipta.

Sochibin, A. 2009. Penerapan Model Pembelajaran Inkuiri Terpimpin Untuk Peningkatan Pemahaman Dan Keterampilan Berpikir Kritis Siswa Sd. Jurnal Pendidikan Fisika Indonesia. 5 (2009): 96-101. Universitas Negeri Semarang. 